\title{
The distribution of autobiographical memories across the lifespan
}

\author{
DAVID C. RUBIN and MATTHEW D. SCHULKIND \\ Duke University, Durham, North Carolina
}

\begin{abstract}
Words were used to cue autobiographical memories from 20- and 70-year-old subjects. Both groups showed a decrease in memories from the childhood years and a power-function retention function for their most recent 10 years. Older subjects also had an increase in the number of memories from the ages 10 to 30 . These results held for individual subjects as well as grouped data and held when either 124 or 921 memories were cued. Reaction times to produce memories were constant across decades except for childhood where they were longer.
\end{abstract}

The goals of this project were to study the distribution of autobiographical memories across the adult lifespan in order to (1) test the reliability of earlier findings while excluding artifactual explanations, (2) quantify such findings as precisely as possible while assessing the scope of individual differences that would limit general statements, and (3) try to understand the recall of autobiographical memories in terms of current methods and theories of cognitive psychology. In past research, similar distributions have been obtained repeatedly (Holding, Noonan, Pfau, \& Holding, 1986; Hyland \& Ackerman, 1988; Rubin, Wetzler, \& Nebes, 1986). They are of interest here because they can be analyzed in terms of three theoretically and empirically separate components, one of which still lacks a clear explanation in terms of cognitive constructs.

The first component is a retention function described mathematically by the power function $y=a \cdot t^{-b}$ or $\log (y)=-b \cdot \log (t)+\log (a)$. We choose the power function because it is what Crovitz and Schiffman (1974) used in the first quantitative description of the distribution of autobiographical memories since Galton (1879), and because it provided the best overall fit when compared with the linear, logarithmic, and exponential functions in Rubin (1982) and Rubin and Wenzel (1996). Competing functions, such as the exponential in $\sqrt{t}$, the hyperbolic, and the hyperbolic in $\sqrt{t}$, provide slightly better fits for some experiments and thus cannot be ruled out, but in most studies the power function provides the best overall fit, usually leaving less than $5 \%$ of the variance unexplained. Although differences in fit exist between autobiographical memory and laboratory episodic retention functions (Rubin \& Wenzel, 1996), the power

Support for this study was provided by NIA Grant AG04278 and the Duke University Arts and Science Research Council. Thanks are extended to Kevin Mallory for testing the subjects and performing the initial data reduction. Reprints are available from D. C. Rubin. Department of Experimental Psychology, Duke University, Durham NC 27708-0086 (e-mail: rubin(a)psych.duke.edu). function also provides one of the best fits to laboratory retention studies (Anderson \& Schooler, 1991; Rubin \& Wenzel, 1996; Wickelgren, 1975; Wixted \& Ebbesen, 1991), and so it can describe retention from both kinds of episodic memory studies. We return to the issue of the best-fitting function when we discuss the results of Experiment 1 , but for now we retain the power function as an excellent description of retention.

The power-function retention component is extremely reliable in spite of the lack of controls placed on the subject. Not only do different laboratories produce the same power-function retention function for the most recent decades of life (Rubin et al., 1986), but the function also exists when individual subjects or responses to individual words are analyzed (Rubin, 1982), when visual or olfactory, instead of verbal, cues are given (Rubin, Groth, \& Goldsmith, 1984), and even when the subject produces responses in the absence of any cue words (Rubin, 1982). It holds for the most recent 10 to 20 years of junior high school students, college students, middle-aged, and older subjects (Fitzgerald \& Lawrence, 1984; Rubin et al.'s, 1986, reanalysis of Franklin \& Holding, 1977). Moreover, the slopes of the power function do not vary with age, implying that the retrieval of autobiographical memories is similar for the most recent 20 years of adult subjects' lives independently of their age. This is consistent with the laboratory literature that shows that older adults do not have any large or consistent deficits in retention (Giambra \& Arenberg, 1993; Rubin et al., 1986; Salthouse, 1991; Wickelgren, 1975). That is, in laboratory tasks, as in the autobiographical memory tasks, the rate of forgetting of older and younger adults appears to be the same (or at least very similar), assuming the initial level of encoding is the same.

A second component is a reduction in the memories coming from the earliest years of subjects' lives: an earlychildhood memory or childhood amnesia function. Much work and much more speculation has surrounded this function (Crovitz \& Harvey, 1979; Fivush \& Hamond, 1990; 
Freud, 1899/1950; Nelson, 1993; Wetzler \& Sweeney, 1986; Winograd \& Killinger, 1983), so its boundaries are relatively well known. Here this childhood amnesia is a mathematical necessity needed to force the function describing the distribution to go to zero at birth. Whereas retention is a function of $t$, time measured from an event (i.e., time, $t$, measured in hours ago), childhood amnesia is a function of age or time measured from birth. It is difficult to fit data from people of different ages without both a retention component based on $t$ and a childhood amnesia component based on age at the time of the memory (i.e., current age $-t$ ).

We call the third component the bump. As shown in Figure 1, more autobiographical memories are recalled from when a person is between 10 and 30 years old than would be expected from the other two components. We use the theoretically neutral term "bump" to highlight the empirical nature of this finding and its lack of a suitable theoretical framework. We leave the theoretically richer term "reminiscence" to refer to conscious recollections seemingly done for their own purposes rather than those requested by another or used for the retrieval of information (for recent reviews, see Fitzgerald, 1996, and Webster \& Cappeliez, 1993). The findings using a quantitative definition of a bump are consistent with those in the literature on reminiscence and could add to them. Additionally, people with many forms of amnesia often have better memory for older than for more recent events (e.g., Butters \& Cermak, 1986; Ribot, 1882; Squire, 1987), but there is currently not a good comparison measure of the extent to which such behavior is normal.

The definition of the bump used here was derived from empirical studies of autobiographical memory that used the cue-word technique. The hollow triangles of Figure 1

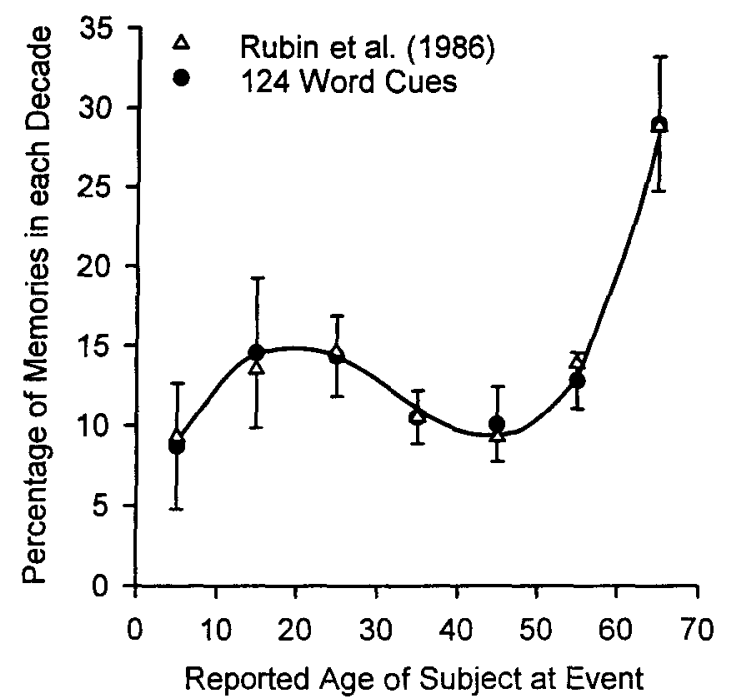

Figure 1. Histogram of autobiographical memories of older subjects of Experiment 1 (solid circles) compared with that of Rubin et al. (1986) (hollow triangles). Error bars show standard errors for Experiment 1 data. were taken from Rubin et al. (1986). They summarize 1,373 memories of 70 adults sorted into the decades in which the individuals reported that the remembered event had occurred. The subjects, who were about 70 years old, were tested in three different laboratories under slightly different conditions (Fitzgerald \& Lawrence, 1984; Franklin \& Holding, 1977; Rubin et al., 1986). At the time of data collection, none of the laboratories were expecting a bump, which appeared only on reanalysis of the data in Rubin et al. (1986). In all cases, the subjects were asked to provide an autobiographical memory for each cue word. There were between 20 and 50 cue words per subject. On completing this task, the subjects were asked to date each memory. Roughly half the memories produced by these subjects are not in Figure 1. Memories that occurred within the most recent year of life were not included, because doing so would have required extending the vertical axis, making the rest of the curve less visible. Data from 50- and 60-year-olds from the same three and one additional laboratory (Zola-Morgan, Cohen, \& Squire, 1983) yielded similar curves. Data from 40-yearolds did not show a clear bump.

Hyland and Ackerman (1988) includes a replication of the bump. Seventy-two individuals ranging in age from 17 to 73 years were cued with object nouns, activity verbs, and feeling terms from Robinson (1976). Older subjects showed a clear reminiscence effect, which peaked in their teens and early $20 \mathrm{~s}$. There were 12 subjects with a mean age of 70 , the age group shown in Figure 1. The distribution of their memories into the 7 decades of their lives was as follows: $2.3 \%, 13.9 \%, 10.2 \%, 7.9 \%, 6.0 \%$, $12.5 \%$, and $47.2 \%$. Thus, there was a bump in the 2 nd and 3 rd decades. Subjects in their 60 s also showed a clear reminiscence effect. Subjects in their 50s showed a possible reminiscence effect, whereas those in their 40s had a nearly equal number of memories from their teens, $20 \mathrm{~s}$, and $30 \mathrm{~s}$, with $80 \%$ of their reports falling in the most recent decade of life.

In addition to the studies finding a bump when autobiographical memories were requested, several researchers found a bump when older subjects were requested to provide either "important" or "vivid" autobiographical memories (e.g., Benson et al., 1992; Cohen \& Faulkner, 1988; Fitzgerald, 1988; Fromholt, Larsen, \& Larsen, 1995; Fromholt \& Larsen, 1991, 1992).

With these studies as an empirical base, we performed two experiments designed to quantify the basic findings outlined as precisely as possible, to assess the scope of individual differences, and to understand the distribution and recall of autobiographical memories in terms of the standard methods and theories of cognitive psychology.

\section{EXPERIMENT 1}

\section{Method}

Subjects. Twenty Duke University undergraduates (12 female) between 20 years 1 month and 20 years 11 months (mean age 20.37) received credit toward their introductory psychology participation requirement or $\$ 5$ per hour. Twenty older adults ( 13 female) between 
the ages of 70 years 1 month and 70 years 11 months (mean age 70.34) were contacted through the Subject Register of the Center for the Study of Aging and Human Development at Duke University Medical Center. They received \$10 per session. Before the experiment began, the 20 - and 70-year-old subjects answered questions that provided the following background information. Their average highest level of education was $13.6(S D=.6)$ and 15.7 $(S D=2.9)$ years, respectively. Their health ratings, as compared with those of other people their own ages, were $1.95(S D=1.05)$ and $1.75(S D=.85)$, respectively, on a scale of excellent (1), good (2), average (3), fair (4), and poor (5). Their ratings of whether their daily activities were in any way impaired because of their health were $1.25(S D=.72)$ and $1.75(S D=.85)$, respectively, on a scale of none (1), a little (2), some (3), a significant amount (4), and a lot (5). Average systolic over diastolic blood pressures were $106 / 68$ and $133 / 78$, respectively. Thus, the groups were healthy, well educated, and, given their large age difference, fairly well matched.

Materials. The 124 words used to cue autobiographical memories were taken from 125 words previously normed on 51 properties (Rubin, 1980). The word "breast" was eliminated from the original 125 words because of the likelihood of its producing a potentially embarrassing autobiographical memory. The 124 cue words were presented in a different random order to each subject.

Procedure. The procedure followed earlier work in this area (e.g., Rubin, 1982; Rubin et al., 1986). The subjects, who were tested individually, were asked to provide one event for each cue word; that is, a memory for an event in their lives that could be specified as having occurred at one particular place and time. The subjects worked at a desk facing a wall so that the experimenter was out of sight. Their reaction times were recorded with a stopwatch from the end of each word being read until the writing of a memory began. The subjects recorded a brief description of the memory. They were asked to try to make the descriptions generally clear and specific, but were told to use initials or other symbols intelligible only to themselves whenever they wished. The subjects were informed that they would return to the memories later in order to answer questions about them. After all 124 cue words had been presented, the subjects were asked to return to and date each of their descriptions. Other tasks following this procedure are not considered here.

\section{Results}

The distribution of memories over the lifespan. The most studied aspect of autobiographical memory data like those collected here is the distribution of memories over time. For the data from the 70 -year-olds, we first plot the percentage of memories that came from each of the seven decades of their lives. Following Rubin et al. (1986), in the decade-histogram analysis, and in this type of analysis only, we exclude all memories dated within 1 year of the experimental session. Because 1,220 of the total of 2,313 dated memories came from this period, including them on the plot would have shrunk the scale considerably. Figure 1 also includes a plot of data from Rubin et al., which is based on a total of 1,373 autobiographical memories older than 1 year from three different laboratories. Here and throughout the paper, the percentage of memories in each decade is plotted to allow comparison among data sets with different numbers of observations.

Two analyses argue for the reliability of the bump. The first is the remarkable agreement between this and the earlier studies. The values obtained here are predicted by the past values in a simple regression analysis with an $r=.994$ and an average absolute magnitude of the resid- uals of $0.5 \%$. As indicated by the standard errors in Figure 1 , such a high degree of correspondence is fortuitous. Second, on the basis of Rubin et al. (1986) and other studies reviewed in the introduction, the bump was defined as an increase in memories from between 10 and 30 previous years compared with surrounding periods. Contrasting the percentage of memories in that 10 - to 29 year period with those from the surrounding two decades produced a $t(19)=3.16^{1}$; for 15 of the 20 subjects, there were more memories in the 20 years of the bump than in the surrounding 20 years; for 2 , there were the same; and for 3 , there were fewer. The strength of this analysis is surprising because it was based on comparisons among a small number of observations, with an average of only 7 memories per subject in each of the four decades.

For both age groups, we can compare the retention of memories over the most recent 10 years. We use logarithmic scales, because in past work (Rubin, 1982; Rubin et al., 1986) the retention function for recent years has been found to be a power function (i.e., a straight line on logarithmic scales). The dating procedure did not distinguish well among memories less than 1 day old, so we excluded the 121 memories for the younger group and the 231 for the older group that were less than 1 day old. This leaves 1,971 memories for the younger group and 1,300 for the older group between 1 day and 10 years. This period of 3,652 days was divided into 10 equal steps on a logarithmic scale, and the number of memories falling within each step was calculated for each group as a whole. Because of the equal-ratio nature of the logarithmic scale, 7 of the 10 points plotted in Figure 2 are based on data from the most recent year, that is, for the data that were omitted from Figure 1.

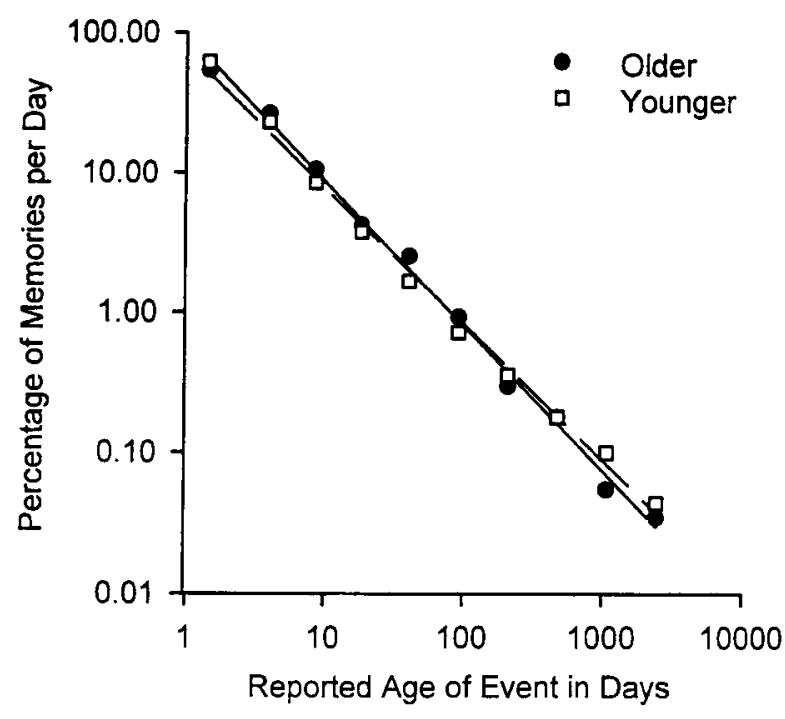

Figure 2. Distribution of most recent 10 years of autobiographical memories of younger and older subjects on log-log coordinates. The vertical axis is the percentage of all the memories generated by each group that fell within each of the 10 equal log intervals between 1 day and 10 years divided by the number of days in that interval. 
Figure 2 agrees with earlier work in that the power function provides a good fit to the data. Using the logarithmic transform of the scales, the linear correlations are .998 and .997 for the younger and older subjects' data sets with slopes of -1.03 and -.97 , respectively. Both the correlations and the slopes are consistent with those found by Rubin et al. (1986) for 15 different data sets, although the slopes are at the high end of the earlier -.83 to -1.05 range. Because the slopes are near -1.00 , a hyperbolic function should fit these data well.

Throughout the rest of the paper, we fit the retention component as a straight line between two logarithmically transformed scales in order to correspond to the figures shown. However, a fairer comparison among functions that would require different transformations of their dependent variables is to fit the nontransformed data and report $r^{2}$, variance-accounted-for figures instead of linear correlations (Rubin \& Wenzel, 1996). For the younger subjects, the $r^{2}$ values for the power, hyperbolic, and exponential functions in the $\sqrt{t}$, the hyperbolic functions in the $\sqrt{t}$, and the exponential, logarithmic, and linear functions are: $.999, .998, .992, .985, .582, .538$, and .098 , respectively. For the older subjects, these values are: .992, $.996, .995, .968, .804, .605$, and .102 , respectively. Thus, as with other studies, the power function provides an excellent fit, much better than the exponential, logarithmic, and linear, but not distinguishable from the hyperbolic and exponential in the $\sqrt{t}$. It is unlikely that curve fitting alone will decide among the best-fitting functions, since descriptions of the data and other theoretical considerations will be needed (Rubin, 1982; Rubin \& Wenzel, 1996). In any case, regardless of whether the transformed or nontransformed data are fit, for Experiment 1, the power function is an excellent description, leaving less than $1 / 2 \%$ of the variance unaccounted for.

Childhood amnesia can also be examined for both age groups. To do this, in Figure 3, we plot the total number of memories at each of the first 10 years of life for both age groups. Both groups show few memories before the age of 3 . The younger subjects increase more steadily than the older subjects, but this may be because they have only the decade shown in Figure 3 and the decade shown in Figure 2 from which to retrieve memories. In contrast, the older adults have 7 decades, and so may retrieve fewer memories from the ages of 7 through 10 .

Reaction times. To interpret the distribution of autobiographical memories, reaction times must be examined. If subjects take longer to find memories in the bump, it may be because they are placing special emphasis on this period, perhaps even by using a conscious search strategy. In contrast, if there is not an increase in reaction time for the bump period, we can conclude that the bump is caused by an increase in memories from this period that are as easy to recall as memories from later periods.

Initial analyses were performed using the arithmetic mean and the geometric mean. As there were minimal differences, throughout the paper we have used the simpler arithmetic mean for reaction times. The younger subjects

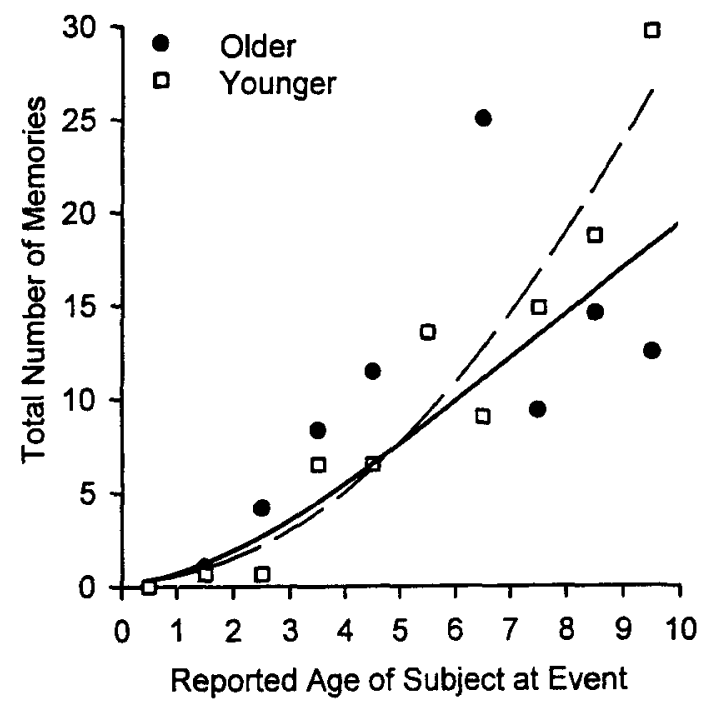

Figure 3. Histogram of autobiographical memories of younger and older subjects for the first 10 years of their lives.

retrieved memories more quickly than the older subjects: $9.5 \sec (S D=3.4)$ versus $16.6 \sec (S D=7.3)[F(1,38)=$ 15.34, $\left.M S_{\mathrm{e}}=32.67\right]$, as expected from the general literature on aging (Cerella, 1985; Salthouse, 1991, 1994) as well as from studies of autobiographical memory (Fitzgerald \& Lawrence, 1984; Holding et al., 1986). Using 5 -year intervals for the younger subjects, instead of decades, because their data were distributed over a shorter period, the main variation across "decades" was statistically significant $\left[F(3,57)=11.31, M S_{\mathrm{e}}=35.51\right]$. However, the variation was caused by an increased reaction time taken to get memories from the "decade" when subjects were youngest. This is the period from which there are the fewest memories. If this "decade" is removed, the variation is no longer significant $\left[F(2,38)=1.41, M S_{\mathrm{e}}=\right.$ 6.17 , n.s.]. Thus, memories from the early childhood period, but not the bump, differ from other memories in their retrieval time. Consistent with this finding, correlations between reaction time and log age of memory were small when each of the dated memories was entered as a data point independent of which subject produced it, $r(2,271)=.05$ for the younger subjects and $r(2,312)=$ .06 for the older subjects.

\section{EXPERIMENT 2}

Two issues are addressed in Experiment 2: whether or not the effects found in group data hold true for individual subjects, and whether or not there are changes in distribution of memories as more memories are accessed (i.e., Does the shape of the histogram change as fewer available memories are accessed?).

\section{Method}

Subjects. Five of the 70-year-olds and 5 of the 20-year-olds from Experiment 1 were selected in a pseudorandom fashion constrained mainly by scheduling considerations. They were paid $\$ 10$ per session. 
Procedure. Eight additional weekly sessions continued after the procedure described in Experiment 1 was completed. In each session, 100 cue words drawn from Paivio, Yuille, and Madigan's (1968) norms of 925 nouns were presented. The 124 words already used and 4 words that might cause embarrassment were excluded (bosom, breast, brassiere, and impotency), so that the final session had only 97 words. This experiment was combined with the previous one to yield a maximum of 921 dated memories per subject. The memory evoked by each word in a session was recorded, and then all the memories produced in that session were dated. The only measures obtained were reaction times and dates.

\section{Results}

Individual differences. Figure 4 shows the distribution of autobiographical memories for each of the 5 individual 70-year-old subjects. There were $357,699,435$, 50 , and 122 memories excluded, because they were in the most recent year for Subjects $a, b, c, d$, and e, respectively. There is a good deal of variability in the plots, with some subjects having many more memories in the earlier decades than others and some having a local peak in the 10-to-19 decade and others in the 20-to-29 decade. However, all subjects show an increase from the 0 -to-9 decade to the 10-to- 29 period followed by a decline and a rise for the most recent decades.

To examine the retention component, we provide the number of memories each individual dated as being between 1 day and 10 years prior to each testing date and the slope and correlation to log-log fits based on the 10 equal-ratio intervals used in Figure 2 . For the older subjects, a, b, c, d, and e from Figure 4, the number of memories from the most recent 10 years are 139, 279, 649, 582 , and 587 ; the slopes are $-.55,-.73,-.79,-.92$, and $-1.19 ;$ and the correlations are $-.931,-.943,-.987$,

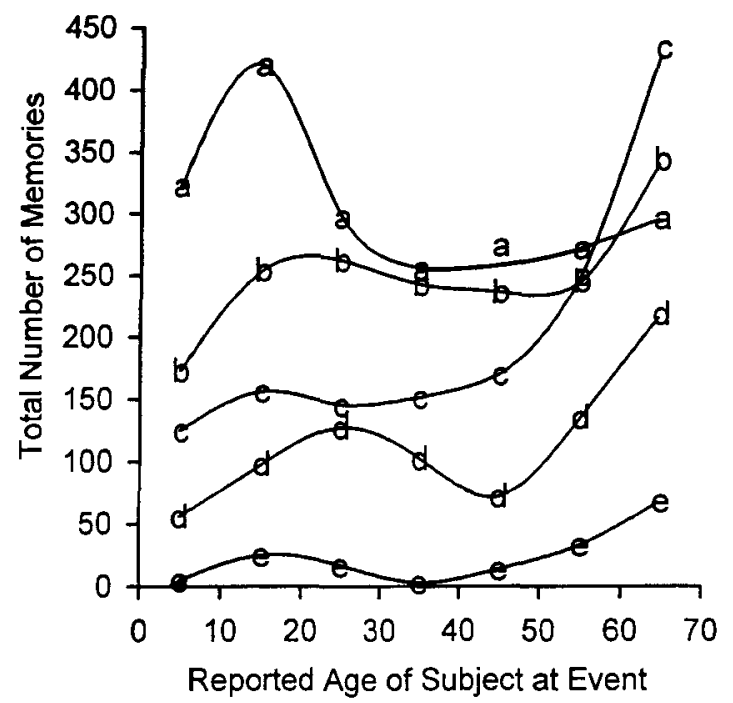

Figure 4. Histogram of autobiographical memories of individual older subjects from Experiment 2. To have all five plots be visible in one figure, successive subjects' plots were each offset by adding memories. Thus, for this figure only, Subject a had 200 memories added to all data points, Subject b had 150 added, Subject $\mathrm{c}$ had 125 added, and Subject $d$ had 50 added.
-.980 , and -.984 . For the younger subjects, the number of memories from the most recent 10 years are 675,803 , 712,841 , and 819 ; the slopes are $-1.14,-1.07,-.55$, -1.05 , and -1.02 ; and the correlations are $-.989,-.993$, $-.977,-.988$, and -.997 . As in previous work (Rubin, 1982), the slopes vary considerably across individuals, but for each individual the fit is good.

Changes over the course of nine sessions. Although the younger subjects had quicker reaction times than the older subjects [7.04 vs. $16.61 \mathrm{sec} ; F(1,8)=20.18]$, there were no reliable changes in reaction time over the nine sessions $[F(8,64)=1.93$, n.s. $]$ and no age $\times$ session interaction $[F(8,64)=1.36$, n.s. $]$.

For the analyses of the distributions of memories, three groups of three sessions were used to provide enough data for smooth distributions. Figure 5 presents data from the older subjects using the methods used in Figure 1. Excluded from the figure are 618,531 , and 514 memories from the first, middle, and last third of the study that were dated within 1 year of their testing session. The methods used in Figures 6 and 7 are the same as those used in Figure 2 to examine the distribution of the most recent 10 years of memories. The slopes and correlations for the first, middle, and last third for the older subjects are, respectively: $-.86, r=-.979 ;-.90, r=-.990$; and -.89 , $r=-.894$. For the younger subjects, they are, respectively: $-.97, r=-.992 ;-1.02, r=-.988$; and -.99 , $r=-.991$. Thus, there appear to be no systematic trends across sessions in the distributions of memories, and no evidence that any aspect of the distribution of autobiographical memories is affected by having close to 1,000 as opposed to close to 100 memories queried.

\section{GENERAL DISCUSSION}

Autobiographical memory is an active and growing field (Conway, 1990; Conway \& Rubin, 1993; Conway, Rubin, Spinnler, \& Wagenaar, 1992; Rubin, 1986, 1996). Here we concentrated on one aspect of autobiographical memory, their distribution over the lifespan. Our findings can be reviewed in terms of our three goals: (1) to test the reliability of earlier findings while excluding artifactual explanations, (2) to quantify such findings as precisely as possible while assessing the scope of individual differences that would limit general statements, and (3) to try to understand the recall of autobiographical memories in terms of current methods and theories of cognitive psychology. We address them in turn.

Although the phenomenon under study is produced under very little experimental control, the results have been extremely regular both within this study and across the literature as a whole. Earlier work (Rubin et al., 1986) identified three components in the distribution of autobiographical memories: childhood amnesia, retention, and an increase in memories from when the subjects were 10 to 30 years old, which we have described with the theoretically neutral term, bump. Childhood amnesia, as used here, is a mathematical result of having subjects of different ages all of whom have few memories from their 


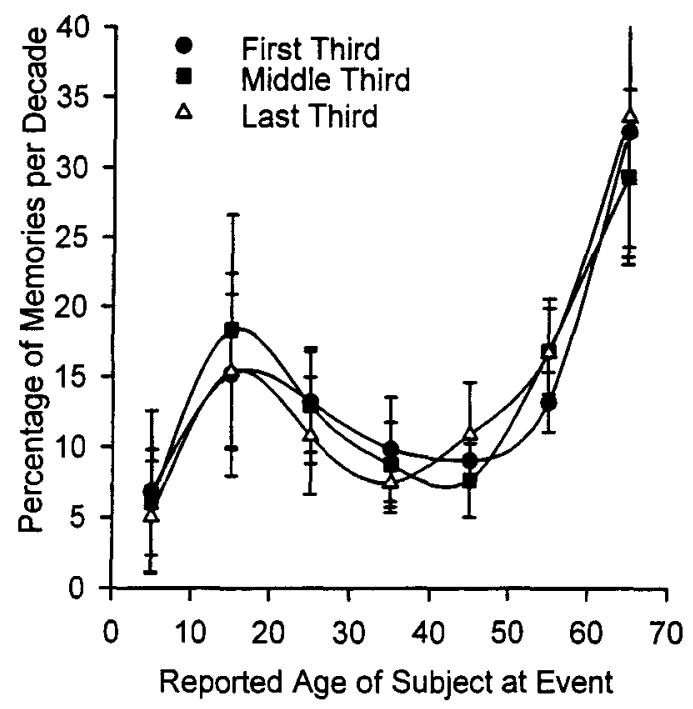

Figure 5. Histogram of the first three, middle three, and last three sessions of the autobiographical memories of 5 older subjects from Experiment 2. Error bars show standard errors.

early childhood and none from before birth. Retention is a monotonic decrease in memories, which follows a power-function loss. As with earlier studies reviewed in Rubin et al. (1986), there was an extremely good fit here to a power function with correlations above .99 for groups of subjects and correlations above .97 for younger individuals and .93 for older individuals. The bump observed here occurred to the same extent and in the same period of the lifespan as it did in earlier studies.

In a replication of these findings, several artifacts were excluded. First, the retention component occurred in both younger and older individual subjects, and the bump occurred in older individual subjects. This excludes averaging over people as a possible explanation of their origin. Second, subjects did not take longer to retrieve memories from the bump. This excludes an explanation that requires added retrieval effort to produce more memories in the bump. Third, these components occurred in subjects who provided over 900 memories and in the last 300 of those 900 memories, excluding a possible explanation in terms of a few highly salient memories. Thus, it is not surprising that subjects who are asked to recall memories from different periods of their lives for 5 or 10 minutes do not show the large differences in the number of memories coming from each period that were found here (Howes \& Katz, 1992; Rabbitt \& Winthorpe, 1988). There are enough memories in any third or quarter of an adult's life to allow for continuous retrieval for a fraction of an hour without difficulty.

The second goal was to quantify the distribution of autobiographical memories as precisely as possible while assessing the scope of individual differences that would limit this effort. To minimize the variability in the ages within each group and to maximize the agreement between time-ago measures and age-at-the-time-of-theevent measures, a narrow range of ages was used for each group. Younger subjects were between the ages of 20 years, 1 month and 20 years, 11 months. Older subjects were between the ages of 70 years, 1 month and 70 years, 11 months.

Group data agreed extremely well with those from earlier studies, but individual differences, especially in the older subjects, were large. The retention function of all 10 subjects who provided enough data for analyses had good fits to a power function, but the slopes varied widely. All 5 of the older individuals studied in detail showed evidence of a bump, but its peak varied between the 10-to-19 and the 20-to-29 decades and its magnitude varied widely. One of the 5 individuals had more memories in her bump than the other 4 combined. The same was true for the earliest decade. The procedure of using nine sessions each separated by about a week supports the view that such individual differences are stable under our test conditions. Because such individual differences are usually ignored in laboratory paradigms, it is impossible to say whether such a large degree of variation occurs in laboratory tasks. Nonetheless, the results indicate that differences can be expected among autobiographical memory studies using individuals drawn from different populations.

What remains is to understand why such distributions of autobiographical memories occur. The observation that the number of memories recalled diminishes to near zero at birth (i.e., the childhood amnesia aspect of the distribution) and the observation that memories from the most recent 10 years closely follow a retention function that has been proposed for other kinds of memory require little explanation. In contrast, explaining the bump is more difficult. The two better understood components are sufficient for the younger subjects: childhood amnesia and retention. Moreover, these two components do not

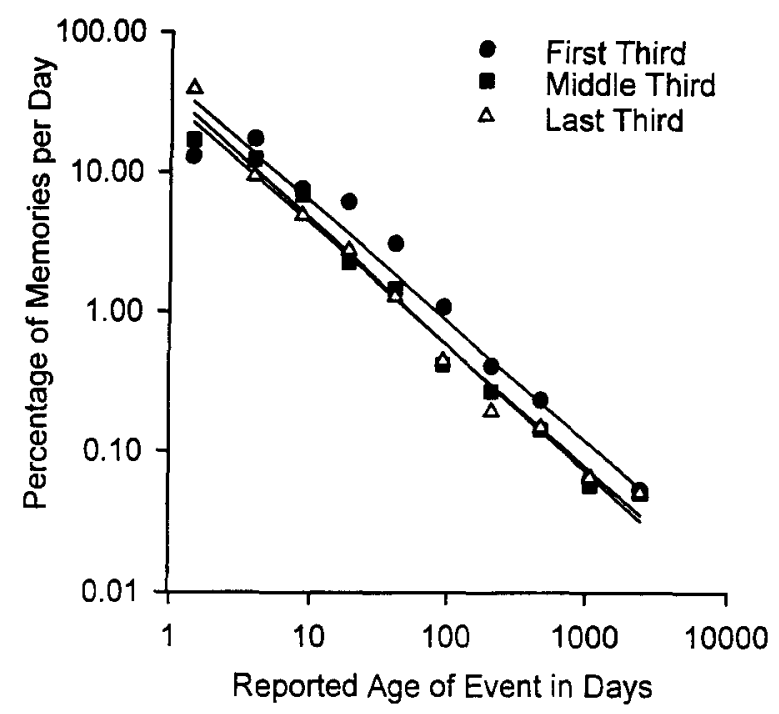

Figure 6. Distribution of the most recent 10 years of autobiographical memories of the 5 older subjects from Experiment 2 on log-log coordinates for the first three, middle three, and last three sessions. 


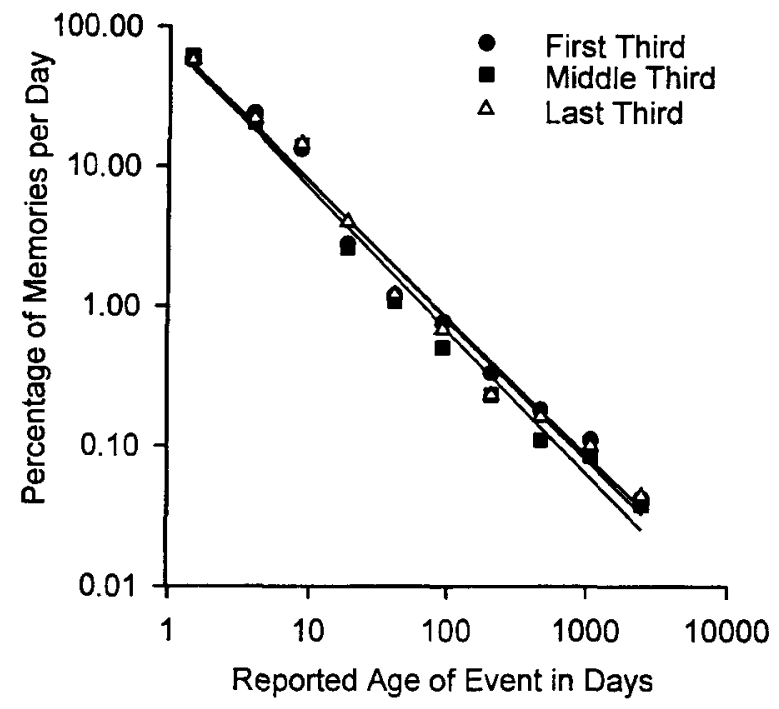

Figure 7. Distribution of the most recent 10 years of autobiographical memories of the 5 younger subjects from Experiment 2 on log-log coordinates for the first three, middle three, and last three sessions.

change when used with the older adults. Given a lack of reaction time differences (and thus perhaps retrieval effort) over the decades described by the retention component, we assume that frequency of recall is a measure of the number of memories that can be retrieved under the cuing conditions given. The resulting retention function suggests that the recall of autobiographical memories is much like the recall of laboratory memories learned under controlled conditions. Recent memories are easier to retrieve and consequently, within the same search times, get retrieved more often. The regularity of the results obtained here within one study and their agreement with existing autobiographical memory and laboratory memory studies should not be overlooked, especially given the lack of control exerted in this study. The power function fits individual subject's data with correlations above .9 and group data with correlations above .99 with no systematic variation in the loss parameter with the age of the subject. Such correlations are not all that common in cognitive psychology.

\section{REFERENCES}

Anderson, J. R., \& Schooler, L. J. (1991). Reflections of the environment in memory. Psychological Science, 2, 396-408.

Benson, K. A., Jarvi, S. D., Arai, Y., Thielbar, P. R. S., Frye, K. J., \& MCDOnALD, B. L. G. (1992). Socio-historical context and autobiographical memories: Variations in the reminiscence phenomenon. In M. A. Conway, D. C. Rubin, H. Spinnler, \& W. Wagenaar (Eds.), Theoretical perspectives on autobiographical memory (pp. 313-322). Dordrecht: Klüwer.

ButTers, N., \& CERMAK, L. S. (1986). A case study of forgetting of autobiographical knowledge: Implications for the study of retrograde amnesia. In D. C. Rubin (Ed.), Autobiographical memory (pp. 253-272). Cambridge: Cambridge University Press.

Cerella. J. (1985). Information processing rates in the elderly. Psychological Bulletin, 98, 67-83.
COHEN, G., \& FaulKner, D. (1988). Life span changes in autobiographical memory. In M. M. Gruenberg, P. E. Morris, \& R. N. Sykes (Eds.), Practical aspects of memory: Current research and issues. Vol. 1. Memory in everyday life (pp. 277-282), New York: Wiley.

Conway, M. A. (1990). Autobiographical memory: An introduction. Milton Keynes, U.K.: Open University Press.

Conway, M. A., \& Rubin, D. C. (1993). The structure of autobiographical memory. In A. E. Collins, S. E. Gathercole, M. A. Conway, \& P. E. Morris (Eds.), Theories of memorv (pp. 103-137). Hove, U.K.: Eribaum.

Conway, M. A., Rubin, D. C., Spinnler, H., \& Wagenaar, W. A. (EDs.) (1992). Theoretical perspectives on autobiographical memory. Dordrecht: Kluwer.

Crovitz, H. F., \& Harvey, M. T. (1979). Early childhood amnesia: A quantitative study with implications for the study of retrograde amnesia after brain injury. Cortex, 15, 331-335.

Crovitz, H. F., \& Schiffman, H. (1974). Frequency of episodic memories as a function of their age. Bulletin of the Psvchonomic Society, 4, 517-518.

FitzGerald, J. M. (1988). Vivid memories and the reminiscence phenomenon: The role of a self narrative. Human Development, 31, $261-273$.

FITZGERALD, J. M. (1996). Intersecting meanings of reminiscence in adult development and aging. In D. C. Rubin (Ed.), Remembering our past: Studies in autobiographical memory (pp. 360-383). Cambridge: Cambridge University Press.

Fitzgerald, J. M., \& Lawrence, R. (1984). Autobiographical memory across the life-span. Journal of Gerontology, 39, 692-699.

Fivush, R., \& HAMOND, N. R. (1990). Autobiographical memory across the preschool years: Toward reconceptualizing childhood amnesia. In R. Fivush \& J. A. Hudson (Eds.), Knowing and remembering in young children (pp. 223-248). New York: Cambridge University Press.

Franklin, H. C., \& Holding, D. H. (1977). Personal memories at different ages. Quarterly Journal of Experimental Psychology, 29, 527-532.

FREUd, S. (1950). Screen memories. In J. Strachey (Ed. \& Trans.), Collected papers (Vol. 5, pp. 47-69). London: Hogarth Press. (Original work published 1899)

Fromholt, P., LARSEN, P., \& LARSEN, S. F. (1995). Effects of late-onset depression and recovery on autobiographical memory. Journal of Gerontology: Psychological Sciences, 50, 74-81.

Fromholt, P., \& LARSEN, S. F. (1991). Autobiographical memory in normal aging and primary degenerative dementia (dementia of the Alzheimer type). Journal of Gerontology: Psychological Sciences, 46, 85-91.

Fromholt, P., \& LARSEN, S. F. (1992). Autobiographical memory and life-history narratives in aging and dementia (Alzheimer type). In M. A. Conway, D. C. Rubin, H. Spinnler, \& W. Wagenaar (Eds.), Theoretical perspectives on autobiographical memory (pp. 413-426). Dordrecht: Klüwer.

Galton, F. (1879). Psychometric experiments. Brain, 2, 149-162.

Giambra, L. M., \& ARENBerG, D. (1993). Adult age differences in forgetting sentences. Psychology \& Aging, 8, 451-462.

Holding, D. H., Noonan, T. K., Pfau, H. D., \& Holding, C. S. (1986). Date attribution, age, and the distribution of lifetime memories. Journal of Gerontology, 41, 481-485.

HowEs, J. L., \& KATZ, A. N. (1992). Remote memory: Recalling autobiographical and public events across the lifespan. Canadian Journal of Psychology, 46, 92-116.

HyLAND, D. T., \& ACKERMAN, A. M. (1988). Reminiscence and autobiographical memory in the study of the personal past. Journal of Gerontology: Psychological Sciences, 43, 35-39.

Nelson, K. (1993). The psychological and social origins of autobiographical memory. Psychological Science, 4, 7-14

Paivio, A., Yuille, J. C., \& Madigan, S. A. (1968). Concreteness, imagery, and meaningfulness values for 925 nouns. Journal of Experimental Psychology, 76(1, Pt. 2), 1-25

RABbitt, P., \& WinTHORPE, C. (1988). What do old people remember? The Galton paradigm reconsidered. In M. M. Gruenberg. P. E. Morris, \& R. N. Sykes (Eds.), Practical aspects of memor?: Current research and issues. Vol. 1. Memory in everiday life (pp. 301-307). New York: Wiley. 
Riвот, T. (1882). Diseases of memory: An essay in the positive psychology (W. H. Smith, Trans.). New York: D. Appleton.

Robinson, J. A. (1976). Sampling autobiographical memory. Cognitive Psychology, 8, 578-595.

RuBin, D. C. (1980). 51 properties of 125 words: A unit analysis of verbal behavior. Journal of Verbal Learning \& Verbal Behavior, 19, 736-755.

RuBiN, D. C. (1982). On the retention function for autobiographical memory. Journal of Verbal Learning \& Verbal Behavior, 21, 21-38.

RuBin, D. C. (ED.) (1986). Autobiographical memory. Cambridge: Cambridge University Press.

RuBIN, D. C. (ED.) (1996). Remembering our past: Studies in autobiographical memory. Cambridge: Cambridge University Press.

Rubin, D. C., Groth, L., \& GoldSMITH, D. (1984). Olfactory cuing of autobiographical memory. American Journal of Psychology, 97, 493-507.

Rubin, D. C., \& WENZEL, A. E. (1996). One hundred years of forgetting A quantitative description of retention. Psychological Review, 103 734-760.

Rubin, D. C., Wetzler, S. E., \& Nebes, R. D. (1986). Autobiographical memory across the adult lifespan. In D. C. Rubin (Ed.), Autobiographical memory (pp. 202-221). Cambridge: Cambridge University Press.

SALTHOUSE, T. A. (1991). Theoretical perspectives on cognitive aging. Hillsdale, NJ: Erlbaum.

SALTHOUSE, T. A. (1994). Aging associations: Influence of speed on adult age differences in associative learning. Journal of Experimental Psychology: Learning, Memory, \& Cognition, 20, 1486-1503.
SQUIRE, L. R. (1987). Memory and brain. New York: Oxford University Press.

Webster, J. D., \& CAPPeliez, P. (1993). Reminiscence and autobiographical memory: Complementary contexts for cognitive aging research. Developmental Review, 13, 54-91.

Wetzler, S. E., \& Sweeney, J. A. (1986). Childhood amnesia: An empirical demonstration. In D. C. Rubin (Ed.), Autobiographical memory (pp. 202-221). Cambridge: Cambridge University Press.

WICKELGREN, W. A. (1975). Age and storage dynamics in continuous recognition memory. Developmental Psychology, 11, 165-169.

WINOGRAD, E., \& KILLINGER, W. A., JR. (1983). Relating age at encoding in early childhood to adult recall: Development of flashbulb memories. Journal of Experimental Psychology: General, 112, 413-422.

WIXTED, J. T., \& EBBESEN, E. B. (1991). On the form of forgetting. Psychological Science, 2, 409-415.

Zola-Morgan, S., Cohen, N. J., \& Squire, L. R. (1983). Recall of remote episodic memory in amnesia. Neuropsychologia, 21, 487-500.

\section{NOTE}

1. All statistical tests are significant at $p<.05$ unless noted as n.s. for not significant.

(Manuscript received December 8, 1995; revision accepted for publication September 18, 1996. 